\section{Category}

Synthesis of

Materials and

Unnatural Products

\section{Key words}

\section{furans}

oligomers

conducting

polymers

electropolymerization

D. SHEBERLA, * S. PATRA, Y. H. WIJSBOOM, S. SHARMA, Y. SHEYNIN, A.-E. HAJ-YAHIA, A. H. BARAK, O. GIDRON, M. BENDIKOV (WEIZMANN INSTITUTE OF SCIENCE, REHOVOT, ISRAEL)

Conducting Polyfurans by Electropolymerization of Oligofurans

Chem. Sci. 2015, 6, 360-371.

\title{
Electropolymerization Furnishes Conducting Polyfuran Films
}

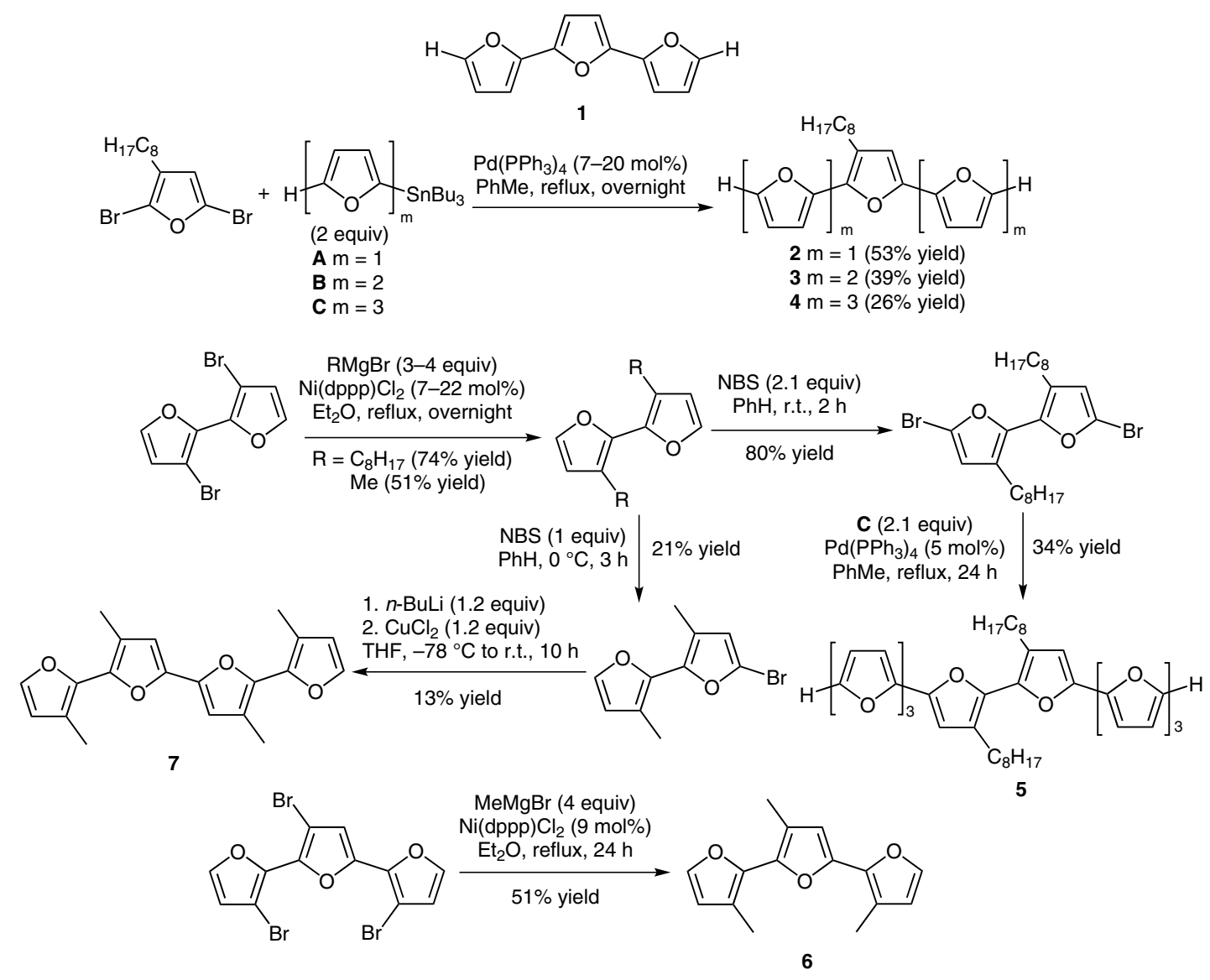

Significance: Polyfurans have received less research attention than their pyrrole and thiophene analogues. This is due in part to the high oxidation potential of furan. Harsh electropolymerization conditions result in defect-rich, non-conducting polyfuran. To lower the potential required to form polyfuran, Sheberla and co-workers synthesize oligofurans 1-7. Potentiostatic polymerization for all of these monomers occurs at $0.75 \mathrm{~V}$ (vs. Ag/ $\mathrm{AgCl})$. The resulting polyfurans are found to have conductivities comparable with electropolymerized polythiophenes.

SYNFACTS Contributors: Timothy M. Swager, Sibo Lin Synfacts 2015, 11(1), 0038 Published online: 15.12.2014 DoI: 10.1055/s-0034-1379665; Reg-No.: S12414SF
Comment: Electropolymerization of furan occurs at potentials in excess of $1.8 \mathrm{~V}$ (vs. $\mathrm{Ag} / \mathrm{AgCl})$. The onset oxidation potentials for $\mathbf{1 - 7}$ are under $0.7 \mathrm{~V}$, and follow expected trends based on conjugation length and degree of alkyl substitution. The highquality polyfurans also undergo oxidative doping at lower potentials than analogous poly(terthiophene)s, resulting in increased stability under the operating conditions. This study may establish polyfuran as a competitor to other conducting polymers. 